\title{
Discussion and Analysis of Water Resources Demonstration in Dashahe
}

\section{Reservoir}

\author{
ZhangXiaojiao ${ }^{1, a}$, LiWanglin $^{1, b}$, LiXinyi ${ }^{1, c}$ \\ ${ }^{1}$ School of Water Conservancy and Environment, University of Jinan, Jinan 250022, China \\ a1055760960@qq.com ,bcswlw@163.com, ${ }^{\mathrm{C}} 649349661 @ q q . c o m$
}

Keywords: water resources demonstration; Dashahe Reservoir; new reservoir; water intake Abstract. The water resources demonstration of Dashahe reservoir in GuanXian of China was analyzed and discussed through this paper. The Dashahe Reservoir project meets the requirements of various national policies and related plans, and the water meets the water consumption control indicator. Therefore, the water intake for the Dashahe Reservoir is reasonable. Wei Canal can meet the demand of reservoir water supply, and the quality of water supply can meet the requirements for water intake in the planning year, so the water source for the water is reliable. As a water intake project, the Dashahe Reservoir has little influence on the spatial and temporal distribution of local water resources and water amount, and its own water withdrawal is water supply, which has little influence on water functional areas and third parties. For water resources demonstration of general construction projects, the focus is on the rationality analysis of water withdrawal, water source verification, and the effects of water withdrawal. However, for the new small-scale reservoir project, it focuses its attention on clarifying the water demand of terminal users, focusing on the analysis of current water use levels, adjusting and calculating the reservoir, and analyzing the impact of water withdrawal.

\section{Introduction}

In order to solve the deficiencies in the comprehensive utilization of water resources in the water resources demonstration work of the construction project, the Ministry of Water Resources of China issued the "Notice on Launching the Pilot Work of Planning Water Resources Argumentation" (hereinafter referred to as the "Notice") in 2010. Prior to the issuance of the "Notice", some domestic scholars conducted a preliminary study on the development of planning water resources demonstration work. For example, after analyzing the necessity and feasibility of planning water resources demonstration, Shi Ruilan ${ }^{[1]}$ and others proposed suggestions on planning water resources management from the aspects of the formulation of regulations, standards, and qualification management. Liu Zhuo ${ }^{[3]}$ and others put forward proposals for establishing a water resources demonstration system for planning from the perspective of water resources management. Chen Qingwei ${ }^{[4]}$ and others conducted a preliminary study of planning water resources demonstration and implementation units and review units from the perspective of water resources management. Zhang Huanlin ${ }^{[5]}$ and others explored the planning of water resources demonstrations in terms of policy frameworks, report review requirements, and other aspects. Through the construction of water resources demonstration projects for construction projects, the construction of high water consuming and heavy pollution projects was controlled from the source, which became an important means for promoting energy-saving and emission-reduction and building a resource-saving and environment-friendly society. 
Based on the proposed the actual situation of water resources argumentation of Dashahe reservoir, focusing on rationality of taking water for the project, water source reliability and the effect of water withdrawal. It can provide reference for the water resources demonstration work of the same type of new small reservoir.

\section{Dashahe Reservoir Overview}

The proposed Dashahe Reservoir project is located in GuanXian, Liaocheng City, Shandong Province. The main role of Dashahe Reservoir is to provide industrial water and landscape water for Qingquan Street, Yanzhuang Street, Chongwen Street and GuanXian Industrial Park. Dashahe Reservoir is a small (1) type plain reservoir, and the newly built reservoir dam, with a crest elevation of $42.90 \mathrm{~m}$. According to the results of the reservoir adjustment, Dashahe Reservoir has an annual storage capacity of 1987.20 million $\mathrm{m}^{3}$; an annual water supply of 1767.2 million $\mathrm{m}^{3}$.The total storage capacity of the reservoir is 983.4 million $\mathrm{m}^{3}$ and the storage capacity is 874.3 million $\mathrm{m}^{3}$. The scope of water resources demonstration for Dashahe Reservoir is shown in Fig. 1.

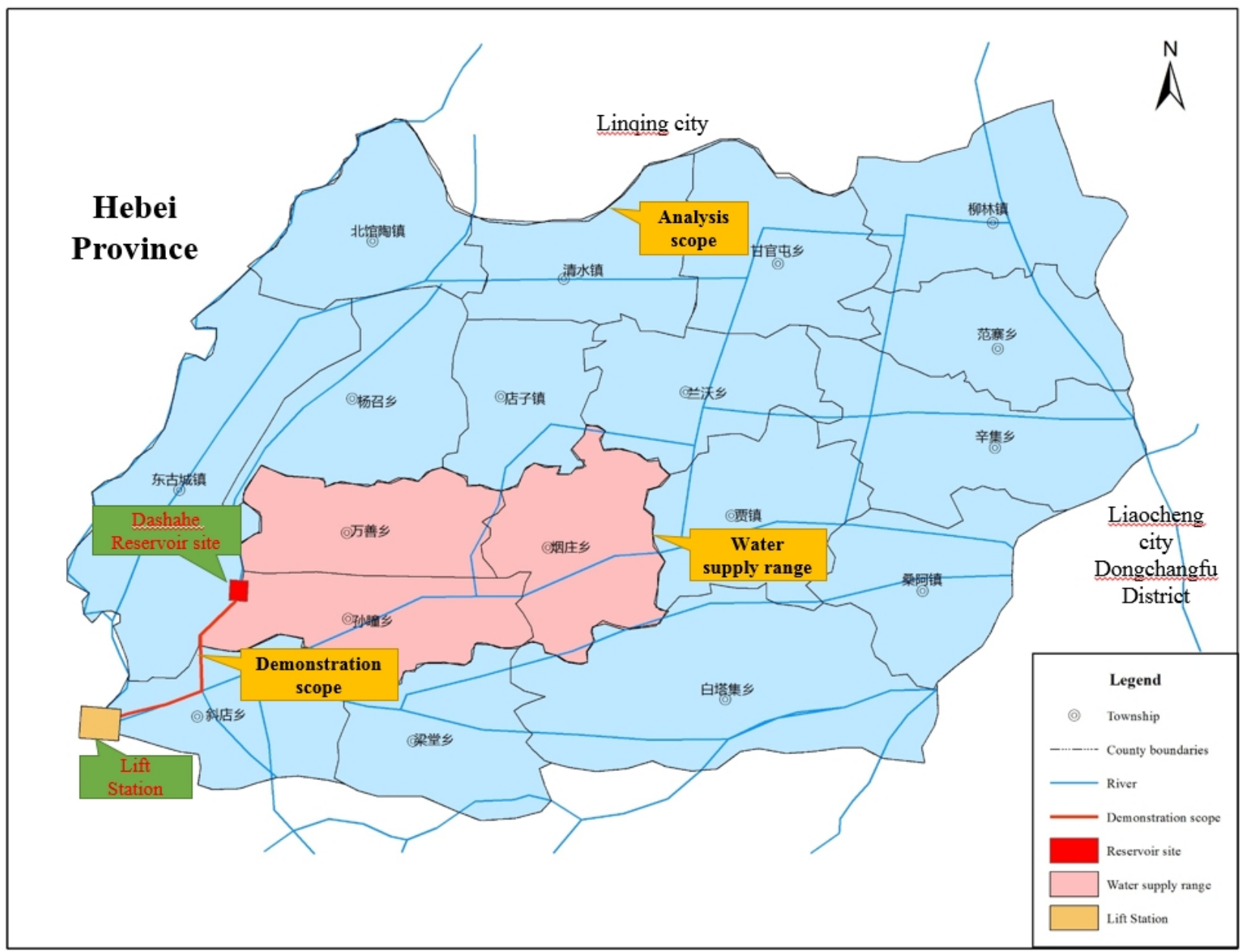

Fig.1 The scope of water resources demonstration

\section{Key Points of Water Resources Demonstration in Dashahe Reservoir}

Water level analysis. The water resources justification of general construction projects only needs to analyze the water consumption of the project, and does not involve other aspects; but the water resources demonstration of the reservoir project involves various sectors of the national 
economy, and it is necessary to analyze the current level of local water use.

According to the data, Guanxian's the water withdrawal per ten thousand Yuan GDP is $70.9 \mathrm{~m}^{3} / \mathrm{ten}$ thousand yuan, and the water use index is higher than the water saving type social control index of Shandong Province. The live use water quota of urban residents in the water supply area of the annual GuanXian is $90 \mathrm{~L} / \mathrm{p} . \mathrm{d}$, and the quota for rural residents' domestic use is $50 \mathrm{~L} / \mathrm{p} . \mathrm{d}$, which is lower than the standard specified in the water-saving social control indicator of Shandong Province. Guan Xian's industrial water consumption was 1326 million $\mathrm{m}^{3}$ in 2015, and the water consumption per million yuan in industrial added value was $11.03 \mathrm{~m}^{3}$, which was slightly higher than the requirement for the industrial water-saving society control index in Shandong Province to increase the value of per million yuan for the industrial added value of $10 \mathrm{~m}^{3}$. Therefore, the level of water use in the water supply area is relatively advanced and meets the requirements of the "Technical Index for the Construction of a Water-saving Society in Shandong Province". The water use for the Dashahe Reservoir meets the requirements for total water consumption control. And the project water use efficiency assessment indicators and the water function area pollution and pollution control indicators are in line with the most stringent water resources management requirements in Shandong Province, Liaocheng City and GuanXian, which can be used to judge the water supply area is reasonable.

Analyze the final water user.As an intermediary process for water intake, the during the analyzes of the water intake, water withdrawal, and rational water use of the reservoir project, have to focuses on analyzing the terminal water users of the reservoir project. It cannot be limited to the reservoir project itself.

Rationality of taking water.The construction of Dashahe Reservoir is in line with the requirements of the national industrial policy and related planning, which is conducive to optimizing the water supply pattern of Guan Xian and the sustainable development of social economy. It is also conducive to the improvement of Guan Xian's ecological environment and can fully utilize the water resources of the Wei Canal.

According to the development plan of the water supply area and the water supply source, the principle of water conservation is used to analyze the water supply and demand, analyze the water demand in the water supply area, and after calculation, in order to meet the industrial water demand in the water supply area and consider the water supply capacity of the Dashahe Reservoir, the reservoir will supply 1524.8 million $\mathrm{m}^{3}$ of water to the industrial area of the water supply area, with a guaranteed rate of $95 \%$. It will supply 242.4 million $\mathrm{m}^{3}$ of ecological water in the water supply area, with a total supply of 1767.2 million $\mathrm{m}^{3}$.

From the above, it can be seen that the construction of the Dashahe Reservoir, through agricultural water-saving, unconventional water development and utilization, replacement of agricultural water indicators for industrial and ecological water use, optimizing the water supply structure, improve the local water use efficiency, so the water is reasonable. The water use indicator of the Dashahe Reservoir is in line with the requirements for the construction of a water-saving social control indicator in Shandong Province. The water used for the project meets the requirements for implementing the most stringent water resources management system. Therefore, the amount of water taken from the construction project is reasonable and can meet the water demand of the water users.

Effect of water withdrawal.The effects of water withdrawal in the demonstration of reservoir water resources include the impact of the reservoir's own withdrawal of water and the effect of water withdrawal from the end of the reservoir.

This project is a centralized urban water supply project. The project itself has no direct water 
withdrawal, and indirect water withdrawal is the user's withdrawal of water in the water supply area during the operation. The annual supply of Dashahe Reservoir to the water supply area is 1412.9 million $\mathrm{m}^{3}$. The greening and ecological replenishment of rivers and lakes do not take into account the withdrawal of water. The industrial production pollution coefficient is calculated as 0.6 , and the average annual sewage volume is 848 million $\mathrm{m}^{3}$. The sewage collection rate is calculated as $98 \%$. The amount of wastewater that can be collected is 831 million $\mathrm{m}^{3}$, which is equivalent to 2.28 million $\mathrm{m}^{3} / \mathrm{d}$. Guanxian County sewage treatment plant is currently designed to handle 6 million $\mathrm{m}^{3} /$ day, which can completely contain the wastewater generated from the industrial water supply in the water supply area. After the sewage treatment, the water discharge standard meets the discharge standard.

The water for domestic and industrial use in the water supply area of the reservoir is treated by the sewage treatment plant and partially reused. Part of the standard is used as ecological water for the river course, and the rest is discharged up to the standard. The discharge standards meet the water quality requirements of the water functional areas and have little impact on the water function areas and third parties.

Reservoir benefit adjustment calculation. When constructing a small-scale reservoir for water source verification, the reservoir should be adjusted and calculated in order to determine the storage capacity of the reservoir and determine whether the water source can meet the reservoir water demand.

Under the premise of ensuring the safety of the reservoir, it is based on the principle of meeting the industrial water demand of the Yanzhuang Street, Chongwen Street, Qingquan Street, and Guanxian industrial parks in GuanXian, as well as the need for urban green sanitation and Qingquan Lake's ecological replenishment needs. According to the main canal water diversion process and the water use process, the adjustment of the reservoir's profitability is calculated. According to the full year adjustment, there will be no water abandonment or water shortage. The adjustment will be carried out from the dead storage capacity. The month will be used as the unit of calculation, starting from December. According to the results of the reservoir adjustment, the Dashahe Reservoir will have an annual storage capacity of 1987.20 million $\mathrm{m}^{3}$, an annual water supply of 1762.92 million $\mathrm{m}^{3}$, and a loss of 220 million $\mathrm{m}^{3}$ of water, of which 122.4 million $\mathrm{m}^{3}$ of water will be lost through evaporation and 97.6 million $\mathrm{m}^{3}$ of leakage loss. The total storage capacity of the reservoir is 983.41 million $\mathrm{m}^{3}$ and the storage capacity is 874.3 million $\mathrm{m}^{3}$.

According to the data, the $50 \%$ guarantee rate is 1.24 billion $\mathrm{m}^{3}$ of water from Wei Canal, the $75 \%$ guarantee rate is 0.72 billion $\mathrm{m}^{3}$, and the $95 \%$ guarantee rate is 0.36 billion $\mathrm{m}^{3}$. The average annual discharge volume of Linqing Section was 1.24 billion $\mathrm{m}^{3}$, the discharge rate at $50 \%$ guarantee rate was 0.94 billion $\mathrm{m}^{3}$, the discharge rate at $75 \%$ guarantee rate was 0.40 billion $\mathrm{m}^{3}$, and the discharge rate at the $95 \%$ guarantee rate was 0.21 billion $\mathrm{m}^{3}$. From the above information, it can be seen that the water from the Wei Canal can meet the diversion requirements of the Dasha River Reservoir. Analysis and demonstration of water sources for Dashahe Reservoir, the Dasha River has an annual storage capacity of 1987.2 million $\mathrm{m}^{3}$, an annual water supply of 1762.92 million $\mathrm{m}^{3}$, and a guaranteed water supply rate of $95 \%$. The planned annual water supply meets the water requirement, and the water source is reliable and feasible.

\section{Discussion}

Compared with the general construction project water resources demonstration, the water resources demonstration of the new small reservoir project pays more attention to the following aspects:

(1)Make clear the final water user's water requirement, analyze its rationality, and determine the 
project water demand;

(2)Pay attention to the rationality analysis of water withdrawal, especially the calculation of the current water level in water consumption analysis;

(3)In the case of water source demonstration for the reservoir, the reservoir should be adjusted and calculated;

(4)The water resources demonstration should strengthen the impact of water withdrawal in water resources verification, including the impact of the reservoir's own withdrawal of water and the impact of water withdrawal from the reservoir's terminal water users.

\section{Conclusion}

According to the water resources argument, the Dashahe Reservoir project meets the requirements of various national policies and related plans, and the water meets the water consumption control indicator. Therefore, the water intake for the Dashahe Reservoir is reasonable; Wei Canal can meet the demand of reservoir water supply, and the quality of water supply can meet the requirements for water intake in the planning year, so the water source is reliable; as a water intake project, the Dashahe reservoir has little influence on the spatial and temporal distribution of local water resources and water amount, and its own water withdrawal is water supply, which has little influence on water functional areas and third parties. As the new small-scale reservoir project, Dashahe Reservoir focuses its attention on clarifying the water demand of terminal users, focusing on the analysis of current water use levels, adjusting and calculating the reservoir, and analyzing the impact of water withdrawal.

\section{Acknowledgements}

This work was financially supported by Shandong province science and technology development plans (2013GSF11606), natural science foundation of Shandong province (ZR2014EFM023) andPublic special scientific Research of Ministry of Water Resources (201401024).

\section{References}

[1] SHI Ruilan, SUN Zhaodong, LIU Yongfeng. Several Understandings of Planning Water Resources Demonstration in China. [J]. Yellow River,2009,31(06):75-76+79.

[2] LIU Yongfeng, SUN Zhaodong, SHI Ruilan. Study on Overall Framework and Contents of Water Resources Appraisal. [J]. Yellow River, 2010, 32(03): 33-34.

[3] LIU Zhuo, CHEN Xian. On the Establishment of Planning Water Resources Argumentation System.[J]. Water Resources Development Research, 2009,9(01):16-19.

[4] CHEN Qingwei, ZHANG Shuling, YANG Cong. Preliminary study of planning water resources demonstration.[J]. Water Resources Development Research, 2010,10(03):33-35.

[5] ZHANG Huanlin, JIANG Guagbin, CHEN Hongwei, ZHANG Dekai. Analysis of the Policy Framework of Planning Water Resources Argumentation J]. Water Resources Development Research, 2010,10(04):53-56. 